\title{
Effect of Cognitive Modelling on Impulsive Behaviour Among Primary School Children
}

\author{
Ivy Kesewaa Nkrumah" ${ }^{1, ~ *, ~ B o l a n l e ~ O l a b i s i ~ O l a w u y i ~}{ }^{2,3}$, Eunice Torto-Seidu ${ }^{1}$ \\ ${ }^{1}$ Department of Psychology, University of Cape Coast, Cape Coast, Ghana \\ ${ }^{2}$ Department of Arts and Social Sciences, University of Ilorin, Kwara State, Nigeria \\ ${ }^{3}$ Centre for Supportive Services for the Deaf, University of Ilorin, Kwara State, Nigeria
}

\section{Email address:}

ivykesewaa@yahoo.com (I. K. Nkrumah), olawuyiolabisi@yahoo.co.uk (B. O. Olawuyi), euniceseidu@gmail.com (E. Torto-Seidu)

\section{To cite this article:}

Ivy Kesewaa Nkrumah, Bolanle Olabisi Olawuyi, Eunice Torto-Seidu. Effect of Cognitive Modelling on Impulsive Behaviour Among Primary School Children. Psychology and Behavioral Sciences. Vol. 4, No. 5, 2015, pp. 174-180. doi: 10.11648/j.pbs.20150405.11

\begin{abstract}
Restlessness has been associated with childhood developmental behaviour. Some children outlive this behaviour while in others, it persist and becomes a problem that prevents them from fulfilling their potentials. If such developmental behaviours are identified early they can be modified, otherwise they develop into serious disorders. Impulsive behaviour is a pervasive characteristic of Attention Deficit Hyperactive Disorder (ADHD), which is known to interfere with successful learning. The present study assessed a cognitive modelling procedure for modifying impulsivity among children. Fifty-four pupils aged between nine and thirteen years were assigned to treatment and control groups. The treatment group received training in cognitive modelling with reflective thinking practices, and the control group was given a placebo in reading comprehension in English. Results revealed superiority in response-time and accuracy (to the Matching Familiar Figures Test20) of the treatment group over the control group. This result subsisted at one month follow-up measures. It is suggested that the school in collaboration with educational psychologists should establish remedial programmes in which reflective procedures could be employed to nurture impulsive children to approach cognitive tasks reflectively.
\end{abstract}

Keywords: Impulsivity, Cognitive Modelling, Reflective Thinking

\section{Introduction}

Biological organisms show a myriad of individual differences in their typical behaviours, emotions and thoughts. Beginning from infancy, individuals vary in traits such as energy and activity levels, positive emotional engagement with others, feelings of distress and irritability, and persistent attention and interest in absorbing tasks (McAdams \& Pals, 2006). This certitude of individual differences is perhaps in no other place more pronounced than in educational settings where differences in variables such as interest, emotion, home background, health, intelligence, age and gender have been shown to have significant influence on educational attainment. Research shows that individuals differ in their responses to cognitive tasks (Kagan, 1971). Some people respond quickly, do not consider alternative responses, and make errors on task especially tasks that require comparisons among alternatives. This stable disposition is described as Impulsivity (Neitfeld \& Bosma, 2003). The opposite of impulsivity is reflectivity.
The reflective child is known to consider alternatives before committing himself or herself to cognitive tasks (Isakson \& Isakson, 1978; Child, 1995; Yu, 1997).

Cognitive Psychologists such as Gargallo (1993), Olasehinde (1991) and Kangro (2011) underscore the merits of the reflective approach in problem solving. They explain that reflective children outperform impulsive ones in cognitive tasks, especially on tasks in which there are several alternatives from which to select the correct ones. Zentall (1993) notes that impulsive children have difficulty withholding active responses and they usually produce academic errors, because they cannot wait long enough to consider alternative information, consequences or responses. The impact of the impulsive problem solving style becomes pronounced in the Ghanaian educational system where examinations at all levels have been dominated by multiple choice items, a test in which impulsive children mostly fail. Impulsive students may therefore not succeed in the Ghanaian educational system, not necessarily because they are less intelligent than the reflective ones but because among other reasons, their impulsivity causes them to guess 
rather than to think. The high failure rate of Ghanaian students on standardized examinations for example, may be largely a result of impulsivity.

Attention to the task at hand and careful consideration of the concepts to be mastered are essential for successful learning. However, this is not always taken into consideration in teaching and testing. Test responses are often the chief basis for diagnosis, yet educational evaluations of children who have difficulties often fail to account for the length of time the child takes to reflect on alternative solutions. There are documented incidents of impulsivity among Ghanaian children although little attention has been given to how it impacts on student achievements. In the Special Attention Project (2011) on learning difficulties, $65 \%$ of teachers, $43 \%$ of headteachers and $62 \%$ of parents who participated in the study rated impulsivity characteristics as the causes of learning difficulties among children. However, educational researchers (e.g., Sumankuuro, 2015, Etsey, 2005; Nyarkoh, 2010) in efforts to combat school failures concentrate on indiscipline, stress, home background, and school infrastructure and facilities as the prevailing factors underpinning the phenomenon. The strategy of modifying cognitive style seems to have been neglected.

The present study assessed a cognitive modelling procedure for training impulsive children in reflective thinking. The following questions guided the study:

a. Can cognitive modelling be effective in the reduction of impulsivity among children?

b. Is behavioural change through cognitive modelling sustainable after cessation of treatment?

\section{Overview of Major Issues}

\subsection{Reflectivity-Impulsivity Dimension of Cognitive Style}

The cognitive style dimension of reflectivity-impulsivity is described by Kagan and his associates (1965) as the tendency for quick, not deliberate response. Reflective children are fastidious and deliberate whereas impulsive children prefer to respond faster without accuracy Yu (1997). Rozencwajg and Corroyer (2005) described reflectivity-impulsivity as a property of the cognitive system that combines individuals' decision making time and their performance in problemsolving situations, which involve a high degree of uncertainty. Reflectivity-impulsivity exists in a bipolar form just like many other stylistic dimensions of individual classification (Bostic, 1988). It describes people at one end of a continuum. Those who respond fast but make more errors are referred to as impulsive, while those who respond slowly and make fewer errors are categorized as reflective. However, there are individuals who respond quickly and yet accurately while there are some others who respond slowly however inaccurately on the same task. For example Watts (2011) studied the effect of visual search strategy and overlays on visual inspection of castings. He identified four groups of individuals: the reflective, impulsive, fast accurate and slow inaccurate. In the sample used by Razmjon and
Mirzaei (2009), the distribution of scores revealed 42 reflectives, 44 impulsives, 34 fast accurates and 10 slow inaccurates. Thus reflectivity-impulsivity is a matter of 'extent' or 'how much' and not whether or not. The dimension does not exist in an all-or-none basis. This is because, while some people display more reflective tendencies, others display more of impulsive ones, yet there are some people who cannot be found in the reflectiveimpulsive bracket; being neither impulsive nor reflective. Kenny (2009), describing this bipolarity of the dimension presented Table 1, which distributes people as follows:

Table 1. Reflectivity-Impulsivity Bipolarity.

\begin{tabular}{lll}
\hline $\begin{array}{l}\text { Impulsive (sacrifice } \\
\text { accuracy for speed) }\end{array}$ & $\begin{array}{l}\text { Slow inaccurate (sacrifice } \\
\text { speed and accuracy) }\end{array}$ & \\
$\begin{array}{l}\text { Fast accurate } \\
\text { (sacrifice speed nor }\end{array}$ & $\begin{array}{l}\text { Reflective (sacrifice speed } \\
\text { for accuracy ) }\end{array}$ & $\begin{array}{l}\text { Median of } \\
\text { Number of } \\
\text { errors }\end{array}$ \\
$\downarrow$ & & \\
Median Latency (seconds to first response) & \\
\hline
\end{tabular}

(Source: adapted from Kenny, 2009, p.53)

\subsection{Potential Causes of Impulsivity: The Biological Versus Environmental Debate}

As is the case with many attention and activity behaviours, there is no specific known cause of impulsivity. One explanation is that as the brain is being developed in a foetus, it undergoes complex and delicate changes. If a woman uses drugs or smokes cigarettes during pregnancy she can vastly alter her foetus's brain chemistry. These chemicals have been shown to cause impulsivity in children (Deliz, 2008). It has even been proposed that a specific gene 5HT2A102 plays an important role in the regulation of impulses. This gene, which contributes to serotonin regulation, has been implicated in ADHD, aggression and suicidal behaviours. Individuals with two of these genes on paired chromosomes score higher on personality tests of impulsivity than those with one or no copies of this gene (Kreisman \& Straus, 2004). According to Werback (1995), deficiencies in several vitamins such as niacin, panthothenic acid, thiamine, and vitamins $\mathrm{B}$ and $\mathrm{C}$ are known to be associated with irritability and impulsivity. Electroencephalograph (EEG) and Position Emission Tomography (PET) scans show that impulsive children have decreased blood flow, glucose utilization and EEG activation (Woods \& Ploof, 1997). Impulsivity has also been shown to be exacerbated by watching too much television, excessive sugar intake, and poor discipline. Inadequate mental stimulation, lack of attention and rejection can intensify signs of impulsivity (Deliz, 2008).

\subsection{Characteristics of Impulse Disorder}

Impulse control disorder is a set of psychological disorders that include: Intermittent explosive disorder- characterized by expression of uncontrollable rage; kleptomania- inability to resist impulsive stealing, pyromania-intense obsession with fire and fire starting; trichotillomania- an irresistible urge to pull one's own hair (American Psychiatric 
Association, 2000). The Parents Handbook (2005) report that children with impulsivity look normal physically and sometimes have normal behaviours. Conversely, they respond to stress by fidgeting, restlessness and distracted behavior. Such children may blurt out inappropriate comments or run into the street without looking. Hinshaw (2005) argues that impulsivity is closely related to the construct of response inhibition and is central to conceptions of both Attention Deficit Hyperactivity Disorder (ADHD) and aggressive-spectrum or disruptive behavior disorders. Impulsivity, or lack of self-control, may be the most problematic and core symptom of ADHD (Schweitzer \& Suler-Azaroff, 1995). It is a common feature of many psychiatric conditions, including bipolar disorder, suicide, borderline personality disorder and conduct disorder (American Psychiatric Association, 2000; van Heerigan, 2001). Teachers who refer to a student as impulsive usually conjure up images of children who rarely stop to think before they fully understand the directions, who often demonstrate remorse when their actions have led to errors or mishaps, who call out frequently in class (usually with wrong answers) and have difficulty organizing their materials (Ziporli, 2008). Nwamuo, (2010) reiterates that an impulsive child's school work may show lack of thought or focus- school papers and assignments are usually incomplete or full of errors.

According to Kaufmann (as cited in Ziporli, 2008), impulsive behaviour is normal in young children, but as they grow older most learn alternative responses. Children later diagnosed as impulsive are those toddlers who run instead of walk, are always on the move and changing focus, and seem to be in perpetual motion without a goal or purpose. Olson, Bates and Bayles (1990) add that two year olds will begin to 'inhibit prohibited actions owing to remembered information' but 'self-regulation' does not develop until the third or fourth grade of life. Because of this, the study focused on class four pupils, who by the Ghanaian Educational Policy are within the ages of 9 and 11 years, a stage where children who are unable to curb automatic reaction could be described impulsive.

\subsection{Reflectivity Versus Impulsivity in Cognitive Problem Solving}

Impulsive children are known to respond in haste when faced with cognitive tasks. They give more attention to being fast than accurate and make more mistakes on cognitive tasks. They have therefore been associated with poor problem solving skills characterized by their hastiness to respond, giving the first answer that comes to mind, and taking decisions without weighing the pros and cons of it (Olasehinde 1991). In his seminal work, Kagan (1965) administered the Matching Familiar Figures Test to children and measured the time it took them to make decisions. He noted that impulsive children took decisions after briefly looking at the figures while the reflective group deliberated on the choices before making a decision. In a related study, Davies and Graff (2006) explored the influence of a reflective-impulsive approach on wholist and analytic processing by counterbalancing presentation of the embedded figures and matching figures subtests of Riding's Cognitive Style Analysis (CSA). Results indicated significant interaction between the presentation order of the subtest and individual differences in reflective-impulsive style. Reflective individuals were significantly more analytic than impulsive individuals when the matching figures subtest was presented first and were marginally but not significantly more wholist when presentation order was reversed. Further, Ying-he and Jia-jia (2011) examined the performance of children identified as reflective-impulsive on three jigsawpuzzle tasks with different complexity and explored individual differences in problem solving and metacognition in reflectiveimpulsive cognitive style. Results were that impulsive children used more steps to solve the problems and tended to complete the puzzle according the main structure, while reflective children preferred inferring according the picture clues. Thus impulsive children prefer the quickest way of resolving cognitive problems because they have dislike of delay and this usually leads to problems in school task.

Fortunately, the impulsive style can be reversed through modelling. Bandura (1969) pioneered the use of modelling to treat phobias, especially for fear of animals such as snakes and dogs. He emphasized that children learn by observing the people around them behave in various ways. If Bandura's theory is valid, then it is predicted that an impulsive child could pay attention to a reflective model to adjust his problematic style. Modelling is a behavioural intervention technique and many clinicians, psychologists and special educators have become interested in using cognitive behavioural techniques in modifying the feelings and behaviours of clients by influencing their patterns of thought or problem solving style. For instance, Nwamuo (2010) used modelling to reduce impulsive behavior of her pupils. A somewhat promising picture arises from the study by Olasehinde (1991), who used modelling to change impulsive cognitive position of some secondary school students. Robinson, Smith, Miller and Brownell (1999) used cognitive behaviour modification and reiterated that cognitive behavioural interventions are effective in modifying inappropriate behaviours and continue to reduce inappropriate behaviour after the cessation treatment.

Following up on these, the present study hypothesized the following:

a. Hypothesis 1: Participants who receive treatment in cognitive modelling with reflective thinking will show reduction in impulsivity at posttest measures.

b. Hypothesis 2: participants who receive the treatment therapy will show reduced impulsivity even after withdrawal of treatment.

\section{Methods}

Subjects: The population for the study was primary school children in Ghana. Primary four pupils were of interest because according to Nwamuo (2010) their age bracket is when impulsivity is fully manifested and their parents and teachers have noticed their inability to stay in one place, 
finish assignments, obey instructions and accomplish tasks required of their age level. The study was conducted at the Roman Catholic School in the Bekwai Municipality. Fifty four pupils (29 females and 25 males) identified as impulsive by the study's rating scales participated in the study. Their age range was 9 to 11 years.

Instruments: Three rating scales were initially used to classify children into reflective and impulsive dichotomies. They were the National Initiative for Children Healthcare Quality- Vanderbilt Assessment Scale for teachers (NICHQVAST), Impulsive Related Questionnaire for Children (IRQC) and the Checklist on Impulsiveness for Parents (CIFP). The Matching Familiar Figures Test-20 (MFFT-20versions $1,2 \& 3$ ) were used for evaluation at pretest, posttest and delayed posttest stages. The MFFT consisted of many items, each of which was familiar to a standard figure. For each figure called the standard, there were five other figures called variants. Although the variants were very similar to the standard, only one was exactly like the standard. The task of the participants was to select from among the variants the one figure that matched the standard.

Design: The experimental research design, specifically the pretest/posttest control group design, was used. Participants were randomly assigned to treatment and control groups. They were pretested to identify their entry behaviours. Interventions for the experimental and control groups followed and post-test was conducted. There was a follow-up assessment at delayed posttest one month after cessation of training. Below is the diagrammatical expression of the design where $\mathrm{R}$ denotes randomization:

$\mathrm{R} \mathrm{O}_{1} \mathrm{X} \mathrm{O}_{2} \mathrm{O}_{3}$

$\mathrm{R} \mathrm{O}_{1}-\mathrm{O}_{2} \mathrm{O}_{3}$

Procedure: The researcher distributed two hundred copies of the NICHQ-Vanderbilt Assessment Scale for teachers to rate pupils. Pupils who scored 20 points and above on the teacher ratings were given the Impulsive Related Questionnaire for Children. Those who scored 10 points and above were ranked impulsive. Parents also rated their children on the CIFC. Three children were not graded as impulsive based on their parents' ratings and they were excluded from the study.

All participants were pretested initially to tap their entry behaviours prior to intervention. The experimental group received training in cognitive modelling with reflective thinking practices and the control group was given reading comprehension tasks in English. Training lasted for six consecutive weeks, with four meeting days in a week and each session lasting for one hour. The experimental group was trained on skills of observation, describing objects and finding relationships and differences between and among objects. The skills of observation and description of objects were repeated. There were classroom progress discussions at regular points. Participants were shown movies of impulsive children and series of interactive discussions were held on the causes and effects of impulsivity based on the movies. They were guided to rehearse the procedure in the reflective problem solving skills of the trainer and feedback was immediately given to them.

Participants were commended for their efforts and encouraged to improve where there were mistakes. Those who did not observe, imitate and perform the task had their break play delayed. Progress verifications were conducted intermittently. New tasks were given and participants were called to demonstrate the procedure to be followed in front of their peers. Reinforcement for minor errors was given and they were asked to observe and correct their errors. They were also trained and encouraged to think things over before they engaged in any task. They were examined on disrupting behaviours (e.g., looking out of the window, leaving their seats, eating in class, etc.) that interfere with learning. To discontinue these behaviour chains, they were encouraged to pay attention in class. There was progress appraisal of cognitive modelling skills, problem solving and questioning, and encouragement and rehearsal.

\section{Results and Discussion}

\subsection{Entry Behaviour of Research Participants}

The Matching Familiar Figures Test (MFFT-20A) took two measures from participants: Response Time (RT) and Error Rate (ER). Impulsivity was described as the length of time the child took to complete the cognitive task and the error rate incurred. If impulsivity was reduced, it was expected that the MFFT would measure a corresponding increase in response time and decrease error rate. An initial pre-test was conducted to determine participants' entry behaviour prior to intervention and it was found that the groups were similar on levels of impulsivity $(p<0.05$, see below).

Table 2. Entry Behaviour of Experimental and Control Groups at Pre-Test Measures.

\begin{tabular}{lllllllll}
\hline & Group & Mean & $\mathbf{t}$ & df & Signific. (2 tail) & Mean Difference & lower & Upper \\
\hline \multirow{2}{*}{ Response Time } & Control & 14.56 & .43 & 52 & .67 & .48 & -1.75 & 2.71 \\
& Experimental & 14.07 & & & & & \\
\multirow{2}{*}{ Error Rate } & Control & 8.04 & -1.56 & 52 & .12 & -1.82 & -4.15 & .52 \\
\hline
\end{tabular}

\subsection{Hypothesis 1}

"Participants in the experimental group will have increased response time and decreased error rate after intervention".

The purpose of this hypothesis was to test the relative efficiency of the treatment variable in the reduction of impulsivity. It was predicted that the experimental group would produce reduced error rate and increased response time at posttest measures. The means and standard deviations for the groups are shown below: 
Table 3. T-test Analysis of Response Time and Error Rate at Posttest Measures.

\begin{tabular}{llllllll}
\hline & Group & N & Mean & SD & df & t & p-value \\
\hline Response & Control & 27 & 13.67 & 6.43 & 52 & 6.70 & .000 \\
Time & Experimental & 27 & 25.26 & 6.28 & & & \\
Error & Control & 27 & 6.15 & 2.88 & 52 & 2.02 & .049 \\
Rate & Experimental & 27 & 4.70 & 2.35 & & & \\
\hline
\end{tabular}

Findings from table 3 indicate that participants in the experimental group had a significantly higher response time and lower error rate compared to their counterparts in the control group at posttest measures $(\mathrm{p}<0.05)$. Evidently, this increased response time and reduced error rate observed in the experimental group are traceable to the effect of the treatment variable employed in the experimental group. Therefore, cognitive modelling has a significant effect in the reduction of impulsivity (increase response time and decrease error rate) among children.

\subsection{Hypothesis 2}

"There is a significant sustainable effect of cognitive modelling on children's impulsivity". The study further tested the stability of the treatment variable on pupils' conceptual tempo by conducting a delayed posttest one month after withdrawal of cognitive modelling. Results of the delayed posttest still revealed superiority of the experimental group over the control group in their performances on the MFFT $(\mathrm{p}<.05)$.

Table 4. T-test Analysis of Response Time and Errors Rate at Delayed Post Test Measures.

\begin{tabular}{llllllll}
\hline & Group & N & Mean & Std. Dev & df & t & p-value \\
\hline Response & Control & 27 & 12.48 & 4.30 & 52 & 7.16 & .000 \\
Time & Experimental & 27 & 21.52 & 4.96 & & & \\
\multirow{2}{*}{ Error Rate } & Control & 27 & 5.70 & 2.83 & 52 & 3.59 & .00 \\
& Experimental & 27 & 3.37 & 1.84 & & & \\
\hline
\end{tabular}

\section{Discussion and Implications}

As described earlier, there are impulsive children in Ghanaian schools. These impulsive children, particularly those used in the study, do not differ in their behaviour characteristics compared to those found in other cultures, as measured by the rating scales. They demonstrate deficits in cognitive problem solving skills compared to the reflective ones. This translates into poor academic performances not necessarily because they are less intelligent than the reflective ones, but because they are unable to regulate their automatic responses.

However as shown in this and previous studies, the disposition can be reversed. The procedures of Self Instructional Training, Programmed Instruction, and Metacognitive support are deemed practicable for modifying impulsivity among individuals. However it appears that the cognitive modelling technique is effective for children, as illustrated in Bandura's (1961) Bobo doll experiment. The present study has demonstrated that an impulsive child could adopt reflective behaviours by observing a reflective model.
The results obtained here agree well with earlier studies such as Gorrel (1993) and Olasehinde (1991).

Another area of interest was whether a behaviour learned through modelling is enduring. To test this, the study conducted a test one month after cessation of training and yet at delayed posttest, the experimental group demonstrated reduced impulsivity compared to the control group. This affirms Robinson et al's (1999) claim that cognitive behaviour interventions continue to reduce inappropriate behaviour after the cessation of treatment. Nwamuo (2010) reported similar results where the effect of modelling was sustained in her research participants after one month follow-up measures.

Based on the results of this study, it is recommended that schools in collaboration with educational psychologists should organize remedial programmes in modelling for children where reflective practices could be taught and its importance emphasized. Teachers and parents should be informed about impulsivity characteristics and strive to identify impulsive children before they develop into unmanageable disorders. Further, teachers and parents should note that they serve as models for children and therefore they have to be conscious of behaviours they display when children are around them. Children learn to imitate, not only teachers and other adults, but their peers as well. Teachers should therefore seat impulsive children close to peers who demonstrate desirable behaviours.

\section{Limitations of the Study}

In spite of the practical value of this study it is limited by the choice of the pre-test/post-test design used in conducting the experiment. The Solomon Four group design could have been ideal to reveal other factors that might have acted as confounds, such as the pretest and influence of teacher's role during training. The researchers however ensured that the procedure followed was distinct for both groups and controlled for characteristics of the models (teachers) such as credentials, teaching methods and gender. Hence, the possible limitation may not have had a limiting effect on the study.

\section{Acknowledgements}

This research was supported by the College of Distance Education, UCC, Ghana, grant to Ivy Kesewaa Nkrumah. However, the content is solely the responsibility of the authors and does not represent official views of the funding institution. The authors would like to thank Professor Brian Haig (University of Canterbury, New Zealand) for the helpful comments on a previous version of this manuscript.

\section{References}

[1] Al-Soulami, T. A. (2004). Cognitive style and creative thinking in Saudi Arabia. Unpublished master's thesis. Um Al Qura University, Makkah, Saudi Arabia. 
[2] American Psychiatric Association. (2000). Diagnostic and statistical manual of mental disorder-text revision. $\left(4^{\text {th }} \mathrm{ed}\right)$. Washington DC: American Psychiatric Association.

[3] Bandura, A. (1961). Transmission of aggression through the imitation of aggressive models. Journal of Abnormal and Social Psychology, 63, 575-582.

[4] Child, D. (1995). Psychology and the teacher. London: Cassel Wellington House.

[5] Davies, J., \& Graff, M. (2006). Wholist-analytic cognitive style: A matter of reflection. Personality and Individual Differences, 41, 989-997.

[6] Deliz, A. (2008). Causes of ADD/ADHD. Retrieved January 9, 2012, from http://abby.deliz.suite101.com/causes-of-addadhd971672 .

[7] Etsey, K. (2005). Causes of low academic performance of primary school pupils in the Shama Sub-Metro of Shama Ahanta East Metropolitan Assembly (SAEMA) in Ghana. Regional Conference on Education in West Africa, Dakar, Senegal.

[8] Gargallo, B. (1993). Basic variables in reflection-impulsivity: A training programme to increase reflectivity. European Journal of Psychology of Education, 8(2), 151-167.

[9] Gorrell, J. (1993). Cognitive modeling and implicit rules: Effects on problem-solving performance. The American Journal of Psychology, 106(1), 51-65.

[10] Hofmann, W., Friese, M., \& Weirs, R. W. (2008). Impulsive versus reflective influences on health behaviour: A theoretical framework and empirical review. Health Psychology Review, 2(2), 111-137.

[11] Isakson, M. B., \& Isakson, R. L. (1978). Modifying impulsivity through training in analysis. The Elementary School Journal, 79, 98-107.

[12] Kagan, J. (1965). Reflection-impulsivity and reading ability in primary grade children Child Development, 36, 609-628.

[13] Kagan, J. (1971). Understanding children: Behaviour motives and thought. New York: Harcourt Brace Jovanovish.

[14] Kangro, E. M. (2011). Interplay of self-control and situational demands in binge-drinking. Abstract submitted at the $2^{\text {nd }}$ Biennial Meeting of the Association Research in Personality, Latvia.

[15] Kenny, R. (2009). Evaluating cognitive tempo in the digital age. Educational Technology Research and Development. 57(1), 45-60.

[16] Kreisman, J. J., \& Hal Straus, M. D. (2004). Living with Borderline Personality Disorder. John Wiley and Sons, Inc.: New Jersey.

[17] McAdams, D. P., \& Pals, J. L. (2006). A new Big Five: Fundamental principles for an integrative science of personality. American Psychologists, 61, 204-217.

[18] Neitfeld, J., \& Bosma, A. (2003). Examining the selfregulation of impulsive and reflective response styles on academic tasks. Journal of Research in Personality, 32, 118140 .

[19] Nwamuo, P. A. (2010). The effect of cognitive modeling in the reduction of impulsive behaviour among primary school children. Ife Psychologia. Retrieved March 12, 2014, from http://periodicals.faqs.org/201003/1973238731.html.

[20] Nyarko, K. (2010). Parental home involvement: The missing link in adolescents' academic achievement. Educational Research, 1(9), 340-344.

[21] Olasehinde, F. A. O. A. (1991). Assessment of procedures for training in reflective thinking in cognitive task performance. Unpublished PhD thesis, University of Ilorin, Nigeria.

[22] Olson, S. L., Bates, J. E., \& Bayles, K. (1990). Early antecedents of childhood impulsivity: The role of parent child interaction, cognitive competence and temperament. Journal of Abnormal Psychology, 18(3), 317-334.

[23] Oviatt, S., Lunsford, R., \& Coulston, R. (2005). Individual differences in multimodal integration patterns: What are they and why do they exist? Beaverton: Origon Health and Science University.

[24] Parents Handbook. (2005). Attention deficit hyperactive disorder. Retrieved May 5, 2015, from http//www.google.com.

[25] Razmjoo, S. A., \& Mirzaei, R. (2009). On the relationship between dimensions of reflectivity/impulsivity as cognitive style and language proficiency among Iranian EFL University students. Iranian Journal of Language Studies, 3(1), 105-124.

[26] Robinson, T. R., Smith, S. W., Miller, D. M., \& Brownell, M. T. (1999). Cognitive behaviour modification of hyperactivityimpulsivity and aggression: A meta-analysis of school-based studies. Journal of Educational Psychology, 91(2), 195-203.

[27] Richfield, S. (2005, October 17). "Parenting and coaching self control and social skills to children". News Organisation. New Mexico: Doughlas main, Eastern New Mexico University Portales.

[28] Rozencwajg, P., \& Corroyer, D. (2005). Cognitive processes in the reflective impulsive cognitive style. Journal of Genetic Psychology, 166(4), 451-463.

[29] Schweitzer, J. B., \& Suler-Azaroff, B. (1995). Self-control in boys with attention deficit hyperactivity disorder: Effects of added stimulation and time. Journal of Child Psychology and Psychiatry, 36(4), 654-661.

[30] Special Attention Project. (2011). Children with learning difficulties in public basic schools in Ghana. A study involving local stakeholders in Greater Accra region. Retrieved June 30, 2012, from http://docsgoogle.com/viewer?acache:EvifwrMkBS:sapghana. com/data

[31] Sumankuuro, J. (2015). An investigation into the academic performance of students in second cycle institution-Northern Ghana. Social Science Research Network, Retrieved March 5, 2015, from http://ssrn.com/abstract=2560214 avan Heeringan, C. (2001). Suicide, serotonin, and the brain. Crisis, 22(2), 6670.

[32] Watt, K. P. (2011). The effect of visual search strategy and overlays on visual inspection castings. Unpublished master's theses, Lowa State University, Ames Lowa.

[33] Werbach, R. M. (1995). Nutritional influences of aggressive behaviour. Journal of Orthomolecular Medicine, 7 (1). Retrieved October 6, 2012, From orthomolecular.org/library/articles/webach.shtml. 
[34] Woods, S. K., \& Ploof, W. H. (1997). Understanding ADHD: Attention deficit disorder and the feeding brain. Sage: Thousand Oaks.

[35] Ying-he, C., \& Jia-Jia, H. (2011). Individual differences in reflective-impulsive cognitive style: Children's problem solving and metacognition. Psychological Development in Education. Retrieved May 9, 2014, from http://en.cnki.com.cn/articleen/CJFDTOTAL-XLFZ201103005.htm.

[36] Yu, K. (1997). The effects of cognitive tempo and training in hypermedia learning environment of navigation patterns, learning achievement, and self-efficacy. Unpublished PhD thesis, Texas Tech. University, Lubbock, TX.

[37] Zentall, S. S. (1993). Research on educational implications of attention-deficit hyperactivity disorder. Exceptional Children, 60(2), 143-153.

[38] Ziporli, T. J. (2008). Excerpt for behaviour management: Application for teachers. Retrieved September 22, 2015, from http://www.education.com/reference/article/impulsive.behavio r-children. 